\title{
MOBILE ACCESS TO PROCESS KNOWLEDGE: AN AGENT-BASED APPROACH
}

\author{
Leendert W. M. Wienhofen \\ CognIT a.s,Meltzersgt. 4, N-0257 Oslo, NORWAY \\ \{Leendert.Wienhofen@cognit.no\}
}

\begin{abstract}
This paper discusses a methodology and its enabling technology using mobile devices and process workflow roles to bring work relevant information directly to users' fingertips. We present one complete solution for knowledge management in the process industry. The proposed solution is accessed from mobile devices and combines a state-of-the-art enterprise knowledge server with a multi-agent system. After a short introduction of the technologies as well as an architecture sketch, three different scenarios in an aluminium production setting are presented. The goal of the presented system is to contribute to knowledge sharing on all levels of the organization.
\end{abstract}

\section{INTRODUCTION}

A large number of process industry enterprises such as Shell, Statoil, Hewlett Packard and Norsk Hydro, have already taken the step to implement knowledge management systems in one way or another 141617. Other large corporations as well as articles in magazines such as Harvard Business Review and the Knowledge Management Magazine also indicate this 311121618. Having control over the knowledge in an enterprise makes it easier to find groups of experts within the organisation which reduces the chances for 're-inventing the wheel' and therefore makes the enterprise more efficient 8.

\subsection{Caveat}

Technology for carrying out the scenarios described in chapter 3,4 and 5 is already available, however the knowledge management system (see paragraph 2.1) and the agent technology (paragraph 2.2) have not yet been combined into one program. Tools for knowledge management from the CORPORUM ${ }^{\circledR}$ suite by CognIT a.s (in particular Knowledge Server and Knowledge Factory 57) have successfully been incorporated at a number of process industries, among others Hydro Aluminium 14and TMG 19. The JADE Multi-Agent System 4has been implemented and tested in the AmbieSense system 12(which includes proximity detection by means of Bluetooth). 


\section{BACKGROUND AND REQUIREMENTS}

Many different ways of describing a knowledge management system exist. Some software vendors claim their groupware solution is a full-fletched knowledge management system. However, software alone will not suffice, it is merely a method to serve the purpose. A full-scale knowledge management approach must embrace the whole organisation including the workers that do not have a desk. Everybody must be a part of the knowledge life cycle.

This paper addresses knowledge management in an industrial context, in particular the situation from the industrial workers $p$ oint of $v$ iew. The a luminium production process, which is referred to in the scenarios, takes place in an approximately 900 meter long production line where the bauxite ore is the input at one end and the products or half-fabricates are the output at the other end. Many processes need to be executed in order to manufacture a product from bauxite ore [9].

Industrial workers, although carriers of vital competence for the industrial plant that employs them, have in general not been recognized as knowledge workers, and therefore have not been included in the knowledge sharing network in a systematic fashion. Their voices a re only heard in meetings where they a re often c onfronted with a situation involving rhetoric that may seem foreign or even hostile to them. We should acknowledge that knowledge workers of this kind have little practice in expressing their ideas and therefore a high percentage of these workers keep their knowledge to themselves and often see this tacit knowledge as inferior to ideas and concepts voiced by trained academics. We should also acknowledge that, as a knowledge worker, the operator (the worker) is a consumer of information; a fact that is often disregarded both by the management and by the worker himself. The result typically leads to aloofness and organizational detachment. Hence it is a basic objective to bring them in and involve them in ways coined in Nonaka's SECI model 15(see also the end of paragraph 2.1). The majority of the workers in industrial plants have must access to the corporate memory, both as donors as well as receivers. This model describes the knowledge creation of firms as conversion of tacit knowledge into explicit knowledge and vice-versa. The interaction builds to a continuous spiral reaching from individual to organizational level. The SECI model contains the following four elements:

- Socialization, where tacit knowledge is shared through shared experiences.

- Externalization, where tacit knowledge is converted into explicit knowledge with the help of metaphors and analogies.

- Combination, where explicit knowledge is systemized and refined e.g. by utilizing information and communication technologies and existing databases.

- Internalization, where explicit knowledge is converted into tacit knowledge, e.g. by learning by doing.

\subsection{Knowledge Management System}

In order to support the sharing of knowledge, an IT system should be put in place. All of the features mentioned in this paragraph are to be made available to the user 
using platform independent intuitive access (for example by web-interface). Features to be included in this system are:

1) A database for storing work processes (workflow), descriptions and definitions (also called best practice documents). This content is represented in a virtual pyramid shape, value chains being at the top (see Figure 1):

1.1) Value chains, to show the overall workflow.

1.2) Processes, to show a higher level of detail

1.3) Flow charts, to show the workflow in a process. In case the process is carried out by employees with different roles in the organisation, the flow chart is split up horizontally to represent each role in the co-operative work. (examples of a role are "operator" or "procurement manager")

1.4) Process descriptions, to give a crisp textual definition of the process. It defines the input, output and roles associated to the described process.

1.5) Role definitions, a textual description of each role explaining the field of work and the certificates/diplomas needed in order to carry out this role.

1.6) Activity matrices show a step-wise approach to each of the activities in a flow chart. Activity matrices can include links to 'one point lessons', see paragraph 3.2 for a scenario that describes such lessons.

2) Methods for approving and verifying processes in order to ensure content integrity.

3) A database and/or web space for storing procedures. Procedures are documents that for example describe legislation, or steering documents.

4) A feedback database, which is a tool for continuous improvement. See paragraph 3.3 for a scenario describing the use of the feedback database.

5) A process network, which links the work processes and other content to the feedback database. When the feedback function is used, the process network will find the right person to notify.

6) An agent enabled search engine, which crawls both the Internet and the Intranet in order to continuously look for information that is relevant to either processes or procedures.

Workers are gathered from different plants to share their experiences for a particular process (SECI: Socialization and Externalization), which usually are defined as a procedure for each specific plant (SECI: Combination). Together they define the best practice for this process and enter this in the database.

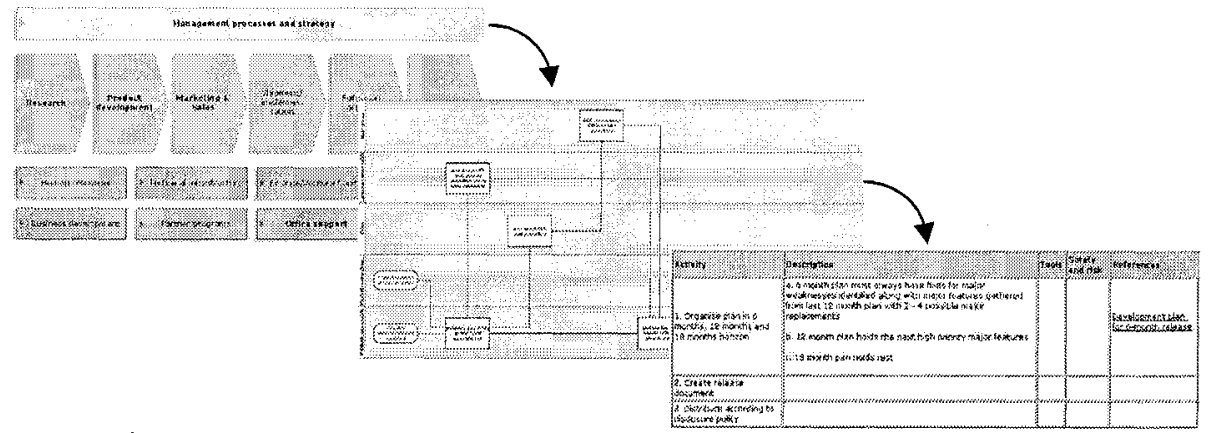

Figure 1: From left to right: Value Chain, Flow Chart, Activity matrix. 


\subsection{Multi-Agent Technology}

Typically vendors supply (parts of the) above-mentioned solution as a portal, where the users must click their way through the content in order to get to the part relevant for them. Yet, the use of a multi-agent system (MAS) enables the user to gain direct access to relevant processes without the need of navigating through the whole value chain and processes.

Ferber 10 writes that an agent can be a physical or virtual entity that can act, perceive its environment (in a partial way) and communicate with others. Further it is autonomous and has skills to achieve its goals and tendencies. A MAS supplies an environment for the agents, defines relations between all the entities, a set of operations that can be performed by the entities and the changes of the universe in time and due to these actions.

In the solution presented (see Figure 2 for a graphical overview), agents work in the background to retrieve knowledge that is relevant to the role and location of the user. This behaviour can be compared to the search agent in the AmbieSense architecture, which uses advanced content retrieval mechanisms as well as casebased reasoning systems in order to retrieve information which is relevant based on the users' context, hereunder location and personal preferences 12 . In case the agent finds more than one knowledge element (such as a flow chart or a one-point lesson describing how to operate a certain machine the operator just passed), it will give the user the option to choose what he/she wants to get more detailed information about. Other than that, the user can also still browse the whole process hierarchy, starting at the value chain level and clicking to the desired level of detail, thereby bypassing the findings of the agent. This way, the user still has full control.

A variety of a gents roam a bout on this sy stem, each of which has a specific task, yet the agents showed in the scenarios are limited to:

- A notification agent, running on the knowledge management platform. This agent sends notifications to employees who can make use of this information because their role is somehow connected to the information. Notifications can be about changes in the process flow, updates in procedures, new feedback, emergency situations, etc. The agent also forwards n ews a bout $\mathrm{p}$ rocedures (for example new legislation), found by the search engine. The use will be explained in more detail in the scenarios in chapter 3 .

- A mobile device agent, running on the mobile device. The mobile device agent is aware of the role of its user, and has different types of behaviours (in order to achieve the $2^{\text {nd }}$ and $3^{\text {rd }}$ behaviour the agent has a direct link into the best practice part of the knowledge management system):

- It reacts on notifications sent by the notification agent and makes sure the receiving system handles the message in an appropriate way (an emergency message will have absolute highest priority and will be displayed on the mobile device directly upon reception. See scenario 2 for a case on handling emergencies).

- Handling of proximity detection of Bluetooth beacons (location awareness), in order to supply the user with relevant process information. 
- Feedback handling

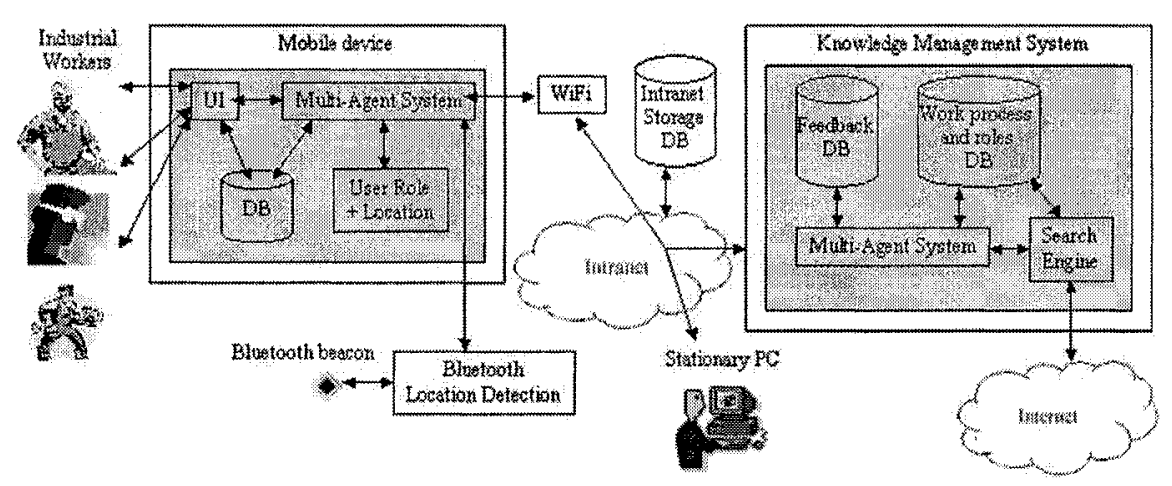

Figure 2 System Architecture

\subsection{Mobile Devices}

Bluetooth 6and WiFi (wireless network) 20enabled mobile devices running agents that are linked to the knowledge management solution, in particular to the role of the user and the process he/she is responsible for in the best practice environment, are to be made available to the industrial workers. An example of a mobile device that can be used is the HP iPAQ Pocket PC h4350.

By placing Bluetooth beacons around in the production hall the mobile device can identify its current location with a 5-10 meter radius. These beacons can be programmed with its exact coordinates and the associated processes in its vicinity. The user of the mobile device no longer has to click his/her way through the value chain in order to reach the relevant process. The mobile device agent automatically finds the processes that are relevant based on location and role of the user, and presents these processes on the mobile device as a list from which the user can pick the one that is most pertinent to the situation. Wireless network access gives the user the ability to access all content of the knowledge management tool and also allows the agents on the mobile device to be able to stay continuously updated and communicate with other agents. A similar approach is used in the AmbieSense project 12.

Stationary computers should be placed at strategic locations such as the lunchroom and control room. The computers that are placed in 'public' areas can be used by all workers to view the content of the knowledge management system (which is r elevant for this p lant) on a screen that is easier to read than the small screens the mobile devices are usually equipped with.

\section{SCENARIO 1: NORMAL USE}

As mentioned in the introduction, the mobile device gives access to all content stored in the knowledge management tool. The user can browse the value chain and processes via the wireless network connection. When the user is near a Bluetooth beacon, a list over relevant information is displayed; this can be the flowchart for the process or a one-point lesson for this particular part of the production line. Since the 
agent on the mobile device is aware of the role of the user, it will only show content that is relevant for this role. An operator will for example not be presented with information on routines or procedures that are not relevant to his/her current function.

Since the screens of mobile devices are not suitable for displaying large amounts of content and large value chains and flowcharts, the user has the possibility to click a button to have the presented information sent as an e-mail to him/herself or to bookmark it. This way the user can access the same information later from a stationary $\mathrm{PC}$.

\subsection{Process News}

The agents on the search engine are always on the lookout for news that is relevant for a process and will automatically publish hits such as a change in legislation (SECI: combination). Process leaders also have the possibility to add news themselves, for example about an upcoming internal seminar on this process' topic. In either case, the news is pushed to the mobile device if relevant for the user.

\subsection{One-point Lessons}

The knowledge management system offers the ability to distribute so called onepoint lessons, which are either one page with very clear instructions or a small video about a particular part in the process, always very focused on just this part. An example of this is how to dispose chemical waste. Since one-point lessons are very focused, they are generally only relevant when the user actually is in the direct vicinity of this process. Since Bluetooth enables proximity-detection, users can automatically be alerted that there is a one-point lesson available. If the user wants to know more about this particular part of the process, he/she can click a button and either read the document or watch the movie clip showing how this task is done (SECI: Internalization). This is especially useful for apprentices who can get a good overview over how processes are carried out.

Another possibility is to equip the mobile device with a camera in order to give the user the possibility to create a one-point lesson video (SECI: Externalization). Before the video is made available to all workers, it needs to be approved by the process responsible. An agent can automatically file the video in the approval queue for this process and will be made available from the point where the video was taken after approval.

\subsection{Feedback}

The feedback database is a very important part of the knowledge management system as it contributes to continuous improvement of the represented processes. Professor Mintzberg from the McGill University has stated 13: "If companies depended on dramatic, top-down change, few would survive. Instead, most organizations succeed because of the small change efforts that begin at the middle or bottom of the company...". This pinpoints the essence of the feedback database, 
which in fact is mostly fed by the people at the bottom of the company, the industrial workers.

When a user finds a mistake in any of the elements of the best practice part of the knowledge management system, he/she $h$ as the ability to send feedback about this issue (SECI: Combination). The user does not need to know who is responsible for the part of the system he/she is supplying feedback to, as this is defined in the process network, meaning the feedback will automatically reach the right person. Other than sending feedback about best practice issues, the user can also submit feedback on the status of machinery, or about very general issues such as the quality of the food in the cantina, etc.

\section{SCENARIO 2: EMERGENCY SITUATION}

An emergency situation occurs; for example triggered when someone pushes an alarm button or a monitoring system has detected that a certain level is over its threshold: Emergency procedures need to be followed. Regardless of which method is used to trigger alarm procedures, the location where the alarm is triggered is always known. Both alarm buttons and sensors have fixed locations and therefore it is possible to know where the nearest Bluetooth beacon is. The alarm will be pushed to the notification agent on the mobile devices that are in the vicinity of the location where the emergency procedure was triggered. An alarm will be broadcasted to the devices (regardless of the role of the user of the device), accompanied by the emergency procedure itself. In addition to the local broadcast, the alarm will also be sent to users that have a role associated with this emergency, regardless of their location. Examples of associated roles are the process responsible, fire fighters and a paramedic team. The superior can either rush to the emergency site, or give orders to the worker via a camera station.

\section{SCENARIO 3: SCHEDULING}

When the agent system is integrated with the groupware solution for e-mail and calendar applications, automated scheduling is a possibility. A notification on an internal seminar (SECI: socialization), as mentioned in the process news scenario, can be accompanied by a button or link to book this event directly in the user's agenda.

\section{CONSIDERATIONS}

Some considerations that need to be addressed when implementing such a system are:

- Possible interference of industrial equipment caused by the use of mobile devices using Bluetooth and WiFi must be investigated.

- Securing access rights, for example: the finance process should not be available other places than in the finance department

- Corporate espionage: How to prevent the competitor from laying hands on 
sensitive information in a wireless network situation?

- Users may get an increased feeling of surveillance, since the location of the mobile device is known.

\section{CONCLUSIONS}

To make sure that every employee in a company contributes to and benefits from the knowledge sharing cycle, everyone must be able to access the corporate memory. By equipping employees with mobile devices linked to a knowledge management solution by means of agent technology the need for the user to search for relevant information can be eliminated, as the relevant information presents itself based on location and the role of the user. This enables the employees to learn much faster about the processes, and by means of the feedback database, give them influence to how to carry out this process in the most effective way. This interaction contributes to knowledge sharing on all levels of the organization, effectively $u$ sing the ideas behind the SECI model.

\section{REFERENCES}

1. AmbieSense Consortium (2003). Deliverable 8, The AmbieSense Multi-Agent System Architecture Report. AmbieSense project, IST 2001- 34244

2. AmbieSense Consortium (2004). Deliverable 9, Intelligent, Personalised Agents for Mobile Use Report. AmbieSense project, IST $2001-34244$

3. Argyris, C. (1991). Teaching Smart People How To Learn. Harvard Business Rev.. May-Jun 91

4. Bellifemine, F. Poggi, A. and Rimassa, G. (2000). Developing multi-agent systems with a FIPAcompliant agent framework. In: Software - Practice And Experience, 2001 no. 31, p. 103-128

5. Bremdal, B., Johansen, F., Spaggiari, C., Engels, R., Jones, R. (1999). Creating a Learning Organisation Through Content Based Document Management. In: Proceedings of Halden Program Group Meeting (HPG-352/12). OECD.

6. The official Bluetooth website, url: http://www.bluetooth.com/

7. CognIT web-site, url: http://www.cognit.no

8. Davenport, T. H., Prusak, L. (1998). Working Knowledge: How Organizations Manage What They Know. Harvard Business School Press.

9. European Aluminium Association, url: http://www.eaa.net/

10. Ferber, J. (1999). Multi-Agent System: An Introduction to Distributed Artificial Intelligence. Harlow: Addison Wesley Longman.

11. Gannon, A. (1998). Knowledge Management at Hewlett-Packard. Knowledge Management Vol 1, \#3 Dec/Jan 1998.

12. Garvin, D. (1998) A. Building a Learning Organisation. Harvard Business Review. Jul-Aug 98.

13. Hesselbein, F., Johnston, R. (2002). On Mission and Leadership, a Leader to Leader Guide. Jossey-Bass, ISBN: 0787960683

14. Hydro Aluminium Metall, ULA Magasin Nr 1-Juni 2001 (pp. 11-19)

15. Nonaka, I. and Takeuchi, H. (1995). The Knowledge-Creating Company: How Japanese Companies Create the Dynamics of Innovation. New York: Oxford University Press.

16. Stata, R. (89). Organisational Learning - The Key to Management Innovation. Sloan Management Review, Spring 1989.

17. Stokke, P. S. and Bremdal, B. A. (1994). Information Refineries and the Manufacturing of Industrial and Corporate Knowledge. Proceedings International Seminar on the Management of Industrial and Corporate Knowledge, ISMICK 94, Compiégne, France.

18. Speh, M. (1998). Kmunity Building at Shell. Knowledge Management Vol 1, \#3 Dec/Jan 1998.

19. TMG International AB, url: http://www.tmg.no

20. WiFi, IEEE standard $802.11 \mathrm{x}$, url: http://www.ieee.org 